\title{
Establishing Comprehensive, Quantitative Criteria for Detection of Restenosis and Remodeling After Percutaneous Transluminal Coronary Angioplasty
}

\author{
Nicoletta B. de Cesare, MD, Paula R. Williamson, BS, Noel B. Moore, BS, Scott F. DeBoe, BS, \\ and G.B. John Mancini, MD
}

\begin{abstract}
To establish comprehensive criteria for detecting restenosis and remodeling, inter- and intraobserver reproducibility of quantilative arteriography in the analysis of $\mathbf{2 0}$ lesions immedlately after and 6 months after percutaneous transluminal coronary angioplasty (PTCA) were assessed. Geometric single-plane (minimum, maximum, mean dlameter and percent dlameter stenosis), biplane (absolute and relative cross-sectional area stenosis), relative densitomelric area stenosis and the average of densilometric area stenosis in orthogonal vlews were compared. A high intra- and interobserver reproduclbility of all absolute measurements was found, with the highest correlations for minimum diameter and cross-sectional area (interobserver, $r=0.85$ and 0.85 ; intraobserver, $r=0.93$, and 0.95 for minimum diameter and cross-sectional area, respectively). Of the relative measurements, biplane seometric percent crosssectional area stenosis was the most reliable and percent densitometric area stenosis was the most variable (interobserver, $r=0.67$; intraobserver, $r=0.71$ ). Only small differences were demonstrated for the absolute measurements between the analysis of lesions immediately after PTCA and after follow-up, whereas a greater variability was found for relative measurements, especially videodensitometry. In both circumstances, a poor correlation between relative densitometric crosssectional area from orthogonal views was found, whereas geometric elliptical cross-sectional area correlated quile well with the average of densitometric percent cross-sectional area in orthogonal views (interobserver, $r=0.86$; intraobserver, $r=0.84$ ). Thus, data in this study support the suitabillty of geometric quantitative analysis for the assessment of PTCA results. Densitometry was the least reliable quantitative parameter.
\end{abstract}

(Am J Cardiol 1992;69:77-83)

From the Department of Internal Medicine, Division of Cardiology, Veterans Administration and University of Michigan Medical Center, Ann Arbor, Michigan. This study was supported in part by the Veterans Administration, Washington D.C. Manuscript received August 23, 1991; revised manuscript received and accepted September 9, 1991.

Address for reprints: G.B. John Mancini, MD, Department of Medicine, University of British Columbia, University Hospital-UBC Campus, Koerner Pavilion, 2211 Wesbrook Mall, Vancouver, British Columbia V6T 2B5.
$\mathrm{V}$ Tisual estimation of coronary stenosis severity is highly variable and unreliable. ${ }^{1-3}$ In an attempt to overcome these limitations, computerized quantitative coronary arteriographic analyses have been described and shown to decrease the amount of observer variability. ${ }^{4-6}$ Quantitative coronary arteriographic methods can be classified as geometric or densitometric. The former are based on the analysis of the geometric diameter of the artery as it is projected onto the intensifier and yield absolute and relative values of cross-sectional area, assuming circular (for single-plane analysis) or elliptical (for biplane analysis) cross-sectional shape of the artery. ${ }^{4-6}$ Videodensitometry methods are based on the concept that the integral of density values across an artery in a radiographic image is proportional to the cross-sectional area at that point and can be used to derive percent area stenosis by comparing the density profile across a normal segment with that across a stenotic segment. ${ }^{7-9}$ Theoretically, this should make the measurements of asymmetric stenoses independent of the projection angle and allow more accurate description of complex lesions with irregular cross-sectional shape.

Interventional techniques, which have become widely used in this last decade, require precise and accurate methods in the evaluation of coronary stenosis dimensions. Moreover, because percutaneous transluminal coronary angioplasty (PTCA) can often produce asymmetric and irregular changes of the vessel lumen, densitometric analysis has been proposed to assess PTCA results. ${ }^{10}$ In these circumstances it has been suggested that geometric assumptions would prevent an accurate and reproducible evaluation of vessel dimensions. On the other hand, a lack of correlation between densitometric measurements in orthogonal views before and after PTCA has been reported. ${ }^{11}$ Also Katritsis et al ${ }^{12}$ demonstrated difficulties with videodensitometry, specifically in evaluation of PTCA results.

The purposes of this study were: (1) to compare the reproducibility of geometric and densitometric quantitative analysis in the assessment of the results of coronary intervention; (2) to evaluate the differences in accuracy and precision for both techniques in the analysis of stenoses immediately after PTCA and of the same lesions after a follow-up of 6 months; and (3) to establish comprehensive, quantitative criteria for the assessment of restenosis and remodeling after coronary interventions. 


\section{MITHODS}

The geometric and densitometric quantitative analysis of 20 lesions immediately after PTCA and after a follow-up of 6 months in 15 consecutive patient studies performed by 2 observers were compared. PTCA was performed on the left anterior descending artery in 10, on the circumflex in 3 , on the obtuse marginal in 4 and on the right coronary artery in 3 cases. Lesions were not preselected on the basis of the location, geometry or ease of computer processing. The only requirement was availability of multiple views, so that a biplane analysis could be performed. The 2 observers analyzed all the lesions twice, independently, immediately after PTCA and after follow-up, with an interval of at least 1 week between the first and the second analysis. The results were then compared with those of a single, long-time user of the software who analyzed all 20 lesions independently and whose results were considered the reference standard for the study. Each of the users had been trained in the use of the software program and the conventions of cineframe selection and digitization used in this laboratory ${ }^{6}$ as well as the Coronary Artery Surgery Study site code. ${ }^{13}$ Choice of the frame, details of digitization, editing of edges and selection of normal reference diameters were completely up to the user's discretion. Only the location of PTCA lesions was given to the observers. Each lesion was analyzed in roughly orthogonal right anterior oblique and left anterior oblique projections. Comparable views were selected for both postPTCA and follow-up analyses. The 20 biplane lesions analyzed immediately after PTCA and at 6 months necessitated digitization of $20 \times 2 \times 2=80$ cineframes for each set of observations. Since the long-time user performed this analysis once and the 2 users did this each twice, 400 cineframes were analyzed for this study.

The imaging procedure and quantification software have been described previously. ${ }^{6}$ Selected frames were projected on a Vanguard viewer optically coupled to a video camera. With a 2.4:1 optical magnification, the subregions of the $35 \mathrm{~mm}$ frame of interest were digitized at $512 \times 512 \times 8$ bit resolution on a digital angiographic computer system (DPS-4100C, ADAC Laboratories, Milpitas, California). To reduce the video noise, 25 video frames were averaged. ${ }^{14}$ All images were subjected to a gray-scale modification to linearly expand their individual scene dynamic range to fill the full 8 bit dynamic range of the digital radiographic system. The digitized film images were digitally magnified by a factor of 2 , through bilinear pixel interpolation, to increase analytic precision in the analysis. Thus, the final overall magnification was $\times 4.8$ and the effective pixel resolution was $2,458 \times 2,458$. The operator selected a circular region of interest with a light-pen cursor and modified the radius of the circle to include the stenotic and the "normal" reference segments. The software then proceeded without operator interaction. The centerline of the arterial segment was determined by analyzing circular pixel density profiles of decreasing radii. Linear density profiles perpendicular to the centerline were then extracted over the entire length of the arterial segment.
Automatic edge detection was accomplished in 2 passes. On the first pass, initial edge points were chosen as points $75 \%$ of the distance between the first and the second derivatives (weighted toward the first derivative) of each perpendicular density profile. During this first pass, incorrect edge points were sometimes generated because of image noise, insufficient contrast or overlying structures. Edge points were automatically checked for spatial continuity and discarded if they were $>4$ pixels distant from neighboring edge points. Threshold density values for valid first-pass edge points were stored for later reference. In the second pass, thresholds for discarded points were calculated using thresholds of adjacent points. Calibration was obtained by measuring the catheter of known size, filled by contrast medium, and determining its edges in the same manner as the arterial segment. After analysis of the lesion in both orthogonal views was completed, the program automatically identified a proximal and distal normal segment and the point of minimum diameter. Automatic selection of proximal and distal segments was accomplished by searching out from the minimum diameter in both directions and finding the point where the artery diameter exceeded $90 \%$ of the difference between the maximi and minimum diameter for that segment. The user had the option to overrule this automatic selection. The final computer results consisted of the geometric minimum diameter, percent diameter stenosis for single-plane analysis, geometric percent area stenosis, and the absolute cross-sectional area assuming an elliptical cross-sectional shape for biplane analysis. In 2 cases, in which an ectatic portion of artery was included in the region of interest, the "normal" reference segment was manually redefined by the operators. Since Ellis et al ${ }^{15}$ had suggested that mean diameter might be the most reliable parameter to quantitate progression of coronary lesions, we also calculated mean and maximum diameters of the segments - automatically and manually determined, respectively - for each lesion in each orthogonal view.

A different portion of the program provided relative videodensitometric cross-sectional area at each point along the centerline by integrating the densities across the perpendicular profile from edge to edge. The edge points were used both as limits for the integration of the individual density profiles and to provide a measure of the typical background densities in this part of the image. Background was subtracted using the edge-point intensities to construct a linearly interpolated approximation for the superimposed background across each profile. For each lesion, videodensitometric percent area stenosis in both orthogonal views and the average of these values were recorded.

Statistical analysis: Student's paired $t$ tests and linear regression analysis were performed for the comparison of stenoses as assessed in single and biplane geometric analysis and in single-plane densitometric analysis. Moreover, the mean difference ("accuracy"), the standard deviation of mean difference ("precision"), mean absolute difference (the average of the values of the dif- 
ference between the 2 readings without concern as to the direction or sign of the difference ["accuracy" previously defined]) and percent absolute difference (the difference between measurements expressed as a percentage of the reference value) were also calculated. These were compared using a repeated-measures analysis of variance, and when overall significance was found, the Newman-Keul test was used to compare the individual parameters with each other. For comparisons that involved biplane observations versus single-plane observations, 2 identical biplane observations were used to correspond with each single-plane observation. A paired $t$ test was used to compare percent biplane geometric cross-sectional area versus percent videodensitometric cross-sectional area stenosis averaged from orthogonal views, because they were the only statistically compared parameters with sample sizes of $\mathbf{4 0}$ (single-plane analyses have a sample size of 80 ). Results were considered significant at $\mathrm{p}<0.05$.

\section{RESULTS}

The inter- and intraobserver variability results did not differ between the 2 test observers and were therefore considered as 1 data set.

A high intra- and interobserver reproducibility was demonstrated for all the absolute measurements (Table I). With regard to relative measurements, percent diameter stenosis showed an excellent reproducibility (interobserver, $r$ value $=0.86$; intraobserver, $r=0.86$ ). Biplane analysis further improved the results of relative geometric single-plane analysis as shown by the better value of $r$ (percent cross-sectional area interobserver, $r=0.89$; intraobserver, $r=0.93$ ), accuracy (percent diameter stenosis: interobserver, -1.35 ; intraobserver, -0.73; percent cross-sectional area: interobserver, -1.16; intraobserver, -0.22 ) and precision (percent diameter stenosis: interobserver, 9.03; intraobserver, 8.1; percent cross-sectional area: interobserver, $r=8.21$; intraobserver, 6.61). None of the accuracy values (mean deviations) were significantly different from zero. In contrast, inter- and intraobserver variability of densitometric area stenosis were quite poor, but by averaging the values obtained in orthogonal views, the reproducibility increased remarkably (interobserver, $\mathrm{r}=$ 0.74; intraobserver, $r=0.84$; accuracy: interobserver, 1.20; intraobserver, 2.15; precision: interobserver, $r=$ 15.00; intraobserver, $\mathrm{r}=12.12$; mean absolute difference: interobserver, 10.84; intraobserver, 8.57). However, these results were still worse than those noted with the geometric analyses.

To allow a comparison of the reproducibility of parameters with different dimensions and number of observations, we also calculated the percent absolute difference (Figures 1 and 2). Both inter- and intraobserver tests showed that mean diameter is the most reliable parameter. Single-plane relative measurements were less reproducible than absolute ones. Videodensitometric percent cross-sectional area was unreliable (interobserver $24.9 \%$, intraobserver $24.5 \%$ ). However, by averaging percent densitometric cross-sectional area in

\begin{tabular}{|c|c|c|c|c|}
\hline & $\begin{array}{l}\text { Min. } \\
\text { Diam. } \\
(\mathrm{mm}) \\
(\mathrm{n}=80)\end{array}$ & $\begin{array}{l}\text { Max. } \\
\text { Diam. } \\
(\mathrm{mm}) \\
(\mathrm{n}=80)\end{array}$ & $\begin{array}{l}\text { Mean } \\
\text { Diam. } \\
(\mathrm{mm}) \\
(\mathrm{n}=80)\end{array}$ & $\begin{array}{c}\text { CSA-G } \\
\left(\mathrm{mm}^{2}\right) \\
(n=40)\end{array}$ \\
\hline \multicolumn{5}{|l|}{ Interobserver: } \\
\hline Mean difference & 0.04 & 0.14 & 0.07 & 0.15 \\
\hline SD of mean difference & 0.41 & 0.81 & 0.49 & 1.21 \\
\hline Mean absolute difference & 0.29 & 0.58 & 0.35 & 0.71 \\
\hline rValue & 0.85 & 0.80 & 0.82 & 0.85 \\
\hline \multicolumn{5}{|l|}{ Intraobsenver } \\
\hline Mean difference & 0.00 & 0.01 & 0.01 & -0.09 \\
\hline SD of mean difference & 0.31 & 0.55 & 0.36 & 0.83 \\
\hline Mean absolute difference & 0.21 & 0.40 & 0.23 & 0.54 \\
\hline \multirow[t]{2}{*}{ r Value } & 0.93 & 0.91 & 0.91 & 0.95 \\
\hline & $\begin{array}{l}\% D S \\
(n=80)\end{array}$ & $\begin{array}{l}\% C S A-G \\
(n=40)\end{array}$ & $\begin{array}{l}\% \text { CSA-V } \\
(n=80)\end{array}$ & $\begin{array}{c}\text { \%CSA- } \\
\text { Vavg } \\
(n=40)\end{array}$ \\
\hline \multicolumn{5}{|c|}{ Overall Variability of Relative Measurements } \\
\hline \multicolumn{5}{|l|}{ Interobserver: } \\
\hline Mean difference & -1.35 & -1.16 & 1.20 & 1.20 \\
\hline SD of mean difference & 9.03 & 8.21 & 18.18 & 15.00 \\
\hline Mean absolute difference & 6.75 & 5.76 & 13.16 & 10.84 \\
\hline rValue & 0.86 & 0.89 & 0.67 & 0.74 \\
\hline \multicolumn{5}{|l|}{ Intraobserver } \\
\hline Mean difference & -0.73 & -0.22 & 2.15 & 2.15 \\
\hline SD of mean difference & 8.10 & 6.61 & 17.94 & 12.12 \\
\hline Mearı absolute difference & 5.94 & 5.52 & 12.83 & 8.57 \\
\hline rValue & 0.86 & 0.93 & 0.71 & 0.84 \\
\hline \multicolumn{5}{|c|}{ 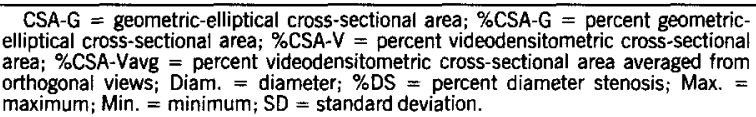 } \\
\hline
\end{tabular}

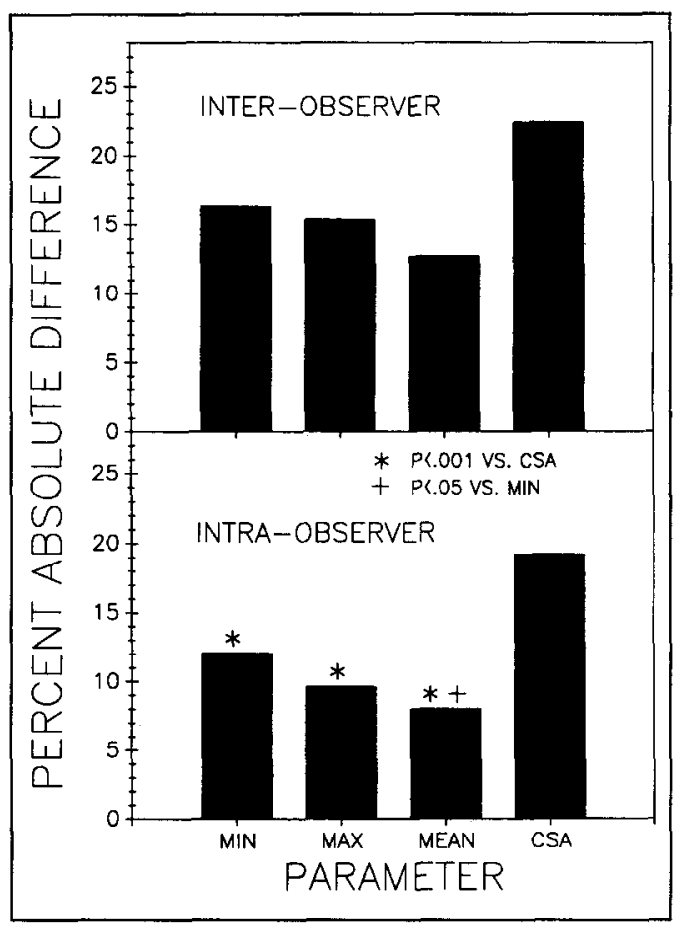

FIGURE 1. Percent absolute differences of the inter- and intraobserver reacts of minimum $(\min )$, maximum $(\max )$ and mean dilameter, and of geometric eflptical cross-sectional area (CSA). 
orthogonal views, a significant reduction of percent mean absolute difference was achieved (interobserver $19.7 \%$, intraobserver $15.1 \%$ ). In biplane analyses, the reproducibility of geometric relative measurements was excellent (interobserver 10.29, intraobserver 9.8).

An analysis was performed to determine the cut-off values of each measurement that could be used in practice to designate a true change in vessel dimensions (as might be caused by restenosis or remodeling of arterial segments) (Table II).

When the measurements obtained in the analysis of lesions 6 months after PTCA and after follow-up were considered separately (Tables III and IV), no relevant differences were demonstrated for both absolute and

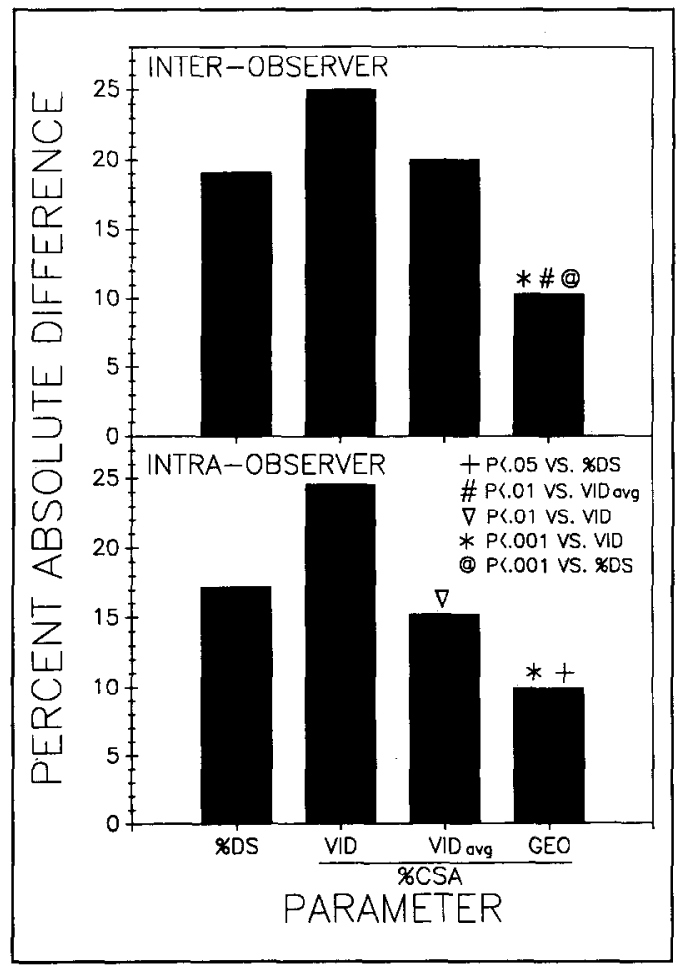

FIGURE 2. Percent absolute differences of the inter- and intracheerver results of the relative measurements. CSA = crose-sectional area; \%DS = percent diameter stenosis; $800=$ percent geometric ellptical cross-sectional area stenchis; VID= percent videodensitometric cross-sectional ares stenosis; Vibavg = percent videodensitometric cross-sectional area stenods averaged from orthogonal views.

TABLE h Summary of Cut-Off Values Proposed to Designate a Change in Vessel Dimensions $(n=80)$

\begin{tabular}{|lcc|}
\hline & \multicolumn{2}{c|}{ Two Times Precision } \\
\cline { 2 - 3 } & Interobserver & Intraobserver \\
\hline Min. diam. (mm) & 0.82 & 0.62 \\
Max. diam. (mm) & 1.62 & 1.10 \\
Mean. diam. (mm) & 0.98 & 0.72 \\
\%DS & 18.06 & 16.20 \\
\%CSA-G & 16.42 & 13.22 \\
\%CSA-V & 36.36 & 35.88 \\
\%CSA-Vavg & 30.00 & 24.24 \\
\hline Abbreviations as in Table l. & & \\
\hline
\end{tabular}

relative measurements. In both post-PTCA and followup films, the correlation between relative densitometric cross-sectional area from orthogonal views was poor $(r=0.67)$ (Figure 3). In contrast, a good correlation $(r=0.85)$ was found between geometric elliptical crosssectional area and the average of percent densitometric cross-sectional area in orthogonal views. Accuracy, precision and mean absolute difference in the analysis of lesions immediately after PTCA and after follow-up are listed in Table V.

\section{Discussion}

Several studies have shown that quantitative coronary angiography is superior to visual estimation in the

\begin{tabular}{|c|c|c|c|c|c|}
\hline & & $\begin{array}{c}\text { Min } \\
\text { Diam. } \\
(n=40)\end{array}$ & $\begin{array}{c}\text { Max } \\
\text { Diam. } \\
(n=40)\end{array}$ & $\begin{array}{c}\text { Mean } \\
\text { Diam. } \\
(n=40)\end{array}$ & $\begin{array}{c}\text { CSA-G } \\
(n=20)\end{array}$ \\
\hline \multicolumn{6}{|l|}{ Interobserver } \\
\hline \multirow[t]{2}{*}{ Mean difference } & (I) & 0.04 & 0.08 & 0.02 & 0.19 \\
\hline & (FU) & 0.05 & 0.02 & 0.11 & 0.11 \\
\hline \multirow[t]{2}{*}{ SD of mean difference } & (I) & 0.41 & 0.89 & 0.52 & 1.41 \\
\hline & (FU) & 0.40 & 0.73 & 0.47 & 1.02 \\
\hline \multirow{2}{*}{$\begin{array}{l}\text { Mean absolute } \\
\text { difference }\end{array}$} & (I) & 0.29 & 0.61 & 0.37 & 0.75 \\
\hline & (FU) & 0.28 & 0.55 & 0.32 & 0.68 \\
\hline \multirow[t]{2}{*}{ r Value } & (l) & 0.84 & 0.80 & 0.83 & 0.83 \\
\hline & (FU) & 0.84 & 0.82 & 0.83 & 0.85 \\
\hline \multicolumn{6}{|l|}{ Intraobserver } \\
\hline \multirow[t]{2}{*}{ Mean difference } & (I) & -0.06 & -0.13 & -0.08 & -0.23 \\
\hline & $(F U)$ & 0.05 & 0.15 & 0.09 & 0.06 \\
\hline \multirow[t]{2}{*}{ SD of mean difference } & (l) & 0.25 & 0.46 & 0.33 & 0.85 \\
\hline & $(F U)$ & 0.35 & 0.60 & 0.38 & 0.81 \\
\hline \multirow{2}{*}{$\begin{array}{l}\text { Mean absulute } \\
\text { difference }\end{array}$} & (1) & 0.16 & 0.34 & 0.21 & 0.49 \\
\hline & (FU) & 0.25 & 0.45 & 0.26 & 0.59 \\
\hline \multirow[t]{2}{*}{ r Value } & (l) & 0.95 & 0.95 & 0.94 & 0.96 \\
\hline & (FU) & 0.90 & 0.89 & 0.88 & 0.93 \\
\hline
\end{tabular}

\begin{tabular}{|c|c|c|c|c|c|}
\hline & & $\begin{array}{c}\% \text { DS } \\
(n=40)\end{array}$ & $\begin{array}{c}\% \text { CSA-G } \\
(n=20)\end{array}$ & $\begin{array}{c}\% \text { CSA-V } \\
(n=40)\end{array}$ & $\begin{array}{c}\% \text { CSA- } \\
\text { Vavg } \\
(n=20)\end{array}$ \\
\hline \multicolumn{6}{|l|}{ Interobserver } \\
\hline \multirow[t]{2}{*}{ Mean difference } & (I) & -0.47 & -0.57 & 2.80 & 2.80 \\
\hline & (FU) & -2.23 & -1.75 & -0.40 & -0.40 \\
\hline \multirow[t]{2}{*}{ SD mean difference } & (I) & 8.71 & 8.66 & 18.65 & 16.80 \\
\hline & (FU) & 9.37 & 7.90 & 17.79 & 13.19 \\
\hline \multirow{2}{*}{$\begin{array}{c}\text { Mean absolute } \\
\text { difference }\end{array}$} & (I) & 6.17 & 6.18 & 13.72 & 12.35 \\
\hline & (FU) & 7.33 & 5.35 & 12.61 & 9.33 \\
\hline \multirow[t]{2}{*}{ rValue } & (I) & 0.78 & 0.82 & 0.52 & 0.56 \\
\hline & (FU) & 0.88 & 0.92 & 0.75 & 0.83 \\
\hline \multicolumn{6}{|l|}{ Intraobserver } \\
\hline \multirow[t]{2}{*}{ Mean difference } & (I) & 0.47 & 0.34 & 1.96 & 1.96 \\
\hline & (FU) & -1.93 & -0.78 & 2.35 & 2.35 \\
\hline \multirow[t]{2}{*}{ SD mean difference } & (l) & 7.53 & 7.28 & 15.86 & 8.77 \\
\hline & (FU) & 8.57 & 5.99 & 20.01 & 14.99 \\
\hline \multirow{2}{*}{$\begin{array}{l}\text { Mean absolute } \\
\text { difference }\end{array}$} & (1) & 6.08 & 6.28 & 12.49 & 7.13 \\
\hline & $(\mathrm{FU})$ & 5.80 & 4.75 & 13.17 & 10.01 \\
\hline \multirow[t]{2}{*}{ r Value } & (1) & 0.84 & 0.87 & 0.70 & 0.88 \\
\hline & (FU) & 0.91 & 0.96 & 0.70 & 0.80 \\
\hline
\end{tabular}


assessment of the severity of coronary lesions. For this reason, quantitative coronary angiography has been largely used in research, whereas in the clinical setting traditional approaches are still widely used. However, a precise assessment of the stenosis severity can provide useful information about prognosis and may help to make therapeutic decisions. ${ }^{16,17}$ Moreover, conclusions derived from studies in which coronary stenosis severity has been measured through quantitative coronary angiography may not be applied to visually estimated stenoses, because of the known differences between quantitative measurements and visual evaluations. ${ }^{18,19}$ On the other hand, it has been suggested that frame and projection selection and other technical factors could decrease the reproducibility of quantitative coronary angiography, making such measurements unsuitable for clinical practice.

Inter- and intraobserver variability studies have often been performed after the selection of the frame to be analyzed, thereby yielding reproducibility values that may not be relevant to clinical use. In our study operators were given only the location of the stenosis to analyze after being trained in conventions used for quantitative analyses. ${ }^{6}$ This freedom of analysis was intended to create a "worst-case" scenario similar to a clinical application of quantitative analyses. Nevertheless, under these conditions the reproducibility of geometric quantitative analysis was excellent.

In a previous study in which the same software was applied to preselected frames, interobserver $r$ values of minimum diameter before and after PTCA were 0.95 compared with 0.84 in the current study (analysis of images before PTCA can be compared with that after follow-up). Therefore, the lack of preselection of the frame, although causing a decrease in reproducibility, does not preclude achievement of clinically reliable results. Moreover, the precision of minimum diameter showed in our study (interobscrver, $0.61 \mathrm{~mm}$; intraobserver, $0.31 \mathrm{~mm})$ is comparable to that $(0.36 \mathrm{~mm})$ found by Reiber et al ${ }^{20}$ in a highly structured research study. Thus, our data completely support the suitability of quantitative coronary angiography when differences in frame selection, reference selection and digitization parameters may differ from observer to observer - as might be expected in clinical practice.

The absolute measures provided by quantitative arteriography are attractive for assessing coronary interventions for several reasons. Studies in humans showed that minimal cross-sectional area can predict the hemodynamic significance of a coronary narrowing more accurately than percent area or percent diameter stenosis. ${ }^{21}$ In addition, our results confirm previous reports ${ }^{11,15}$ showing that absolute measurements are less variable than relative ones. We tested the reproducibility of maximum and mean diameters that theoretically could be used for the follow-up of vessels with no apparent lesions at the baseline or with diffuse disease. Ellis et $a{ }^{15}$ in a study confined to single-plane analyses, showed that mean diameter was the best parameter to assess the evolution of coronary lesions. Our data confirm that mean diameter is highly reproducible.
With respect to minimum diameter, we believe that the slightly greater value of the percent absolute difference can be justified by the smaller magnitude of this measurement (i.e., small differences in this measure-

\begin{tabular}{|c|c|c|c|}
\hline & $\begin{array}{c}\text { Immediately } \\
\text { After PTCA } \\
(n=40)\end{array}$ & $\begin{array}{l}\text { Follow-Up } \\
(n=40)\end{array}$ & $\begin{array}{c}\text { Overall } \\
(\mathrm{n}=80)\end{array}$ \\
\hline \multicolumn{4}{|l|}{ Interobserver } \\
\hline Mean difference & 1.6 & 1.8 & 1.7 \\
\hline SD of mean difference & 10.4 & 10.7 & 10.5 \\
\hline Mean absolute difference & 8.1 & 8.1 & 8.1 \\
\hline r Value & 0.81 & 0.88 & 0.87 \\
\hline \multicolumn{4}{|l|}{ Intraobserver } \\
\hline Mean difference & 2.5 & 0.9 & 1.7 \\
\hline SD of mean difference & 10.2 & 12.5 & 11.4 \\
\hline Mean absolute difference & 8.2 & 9.4 & 8.8 \\
\hline r Value & 0.81 & 0.85 & 0.85 \\
\hline
\end{tabular}

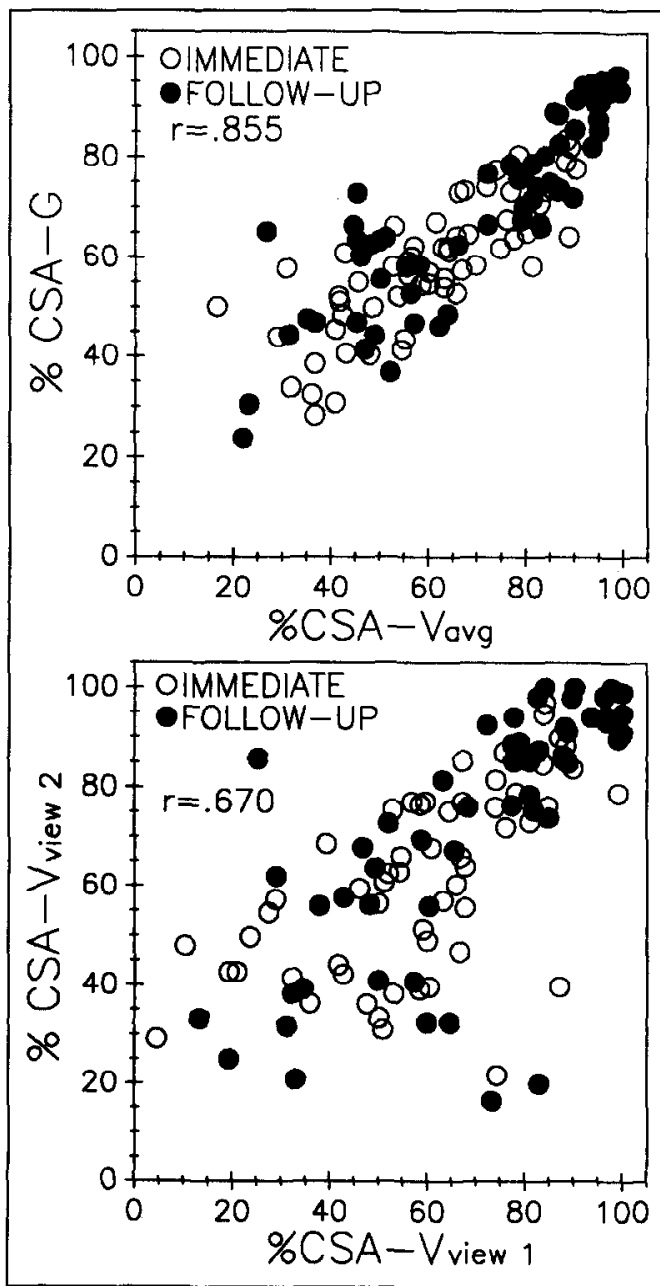

FICURE 3. Linear regrescion analyses of percent geometric allptical cross-sectional area (CSA-G) stenodis and percent vdeodesitometric cross-sectional area stenosis (CSA-V) averaged from orthogonal views (upper panel), and of percent videodenditometric cross-sectional area stenosis from orthogonal views (lower panel) of lesions after percutaneous tranahuminal coronary angioplasty and follow-up. 
ment will appear large when expressed as a percentage). The values of mean absolute difference (interobserver 0.29 , intraobserver 0.21 ) were, in fact, excellent. The low value of mean absolute difference of geometric percent cross-sectional area relative to percent diameter stenosis may be a result of the same phenomenon (i.e., percent cross-sectional area measurements are more severe than percent diameter stenosis measurements because they are proportional to the radius squared). Thus, small differences in the latter would be proportionately larger when expressed as a percentage. We believe that the greater variability of stenosis cross-sectional area than that of minimum diameter can be explained by the fact that the former incorporates errors inherent in measuring minimum diameter in 2 views.

The applicability of geometric quantitative methods to evaluate results after PTCA has been controversial. It has been stressed that irregularities occurring after angioplasty cannot be accurately described by geometric assumptions of circular or elliptical models. Serruys et $\mathrm{al}^{10}$ reported a good agreement between densitometric relative area and geometric single-plane percent stenosis before PTCA, whereas remarkable differences (standard deviation of the difference $=18 \%$ area stenosis) were recorded after PTCA. Because these results were interpreted as related to the complex anatomic changes of the vessel wall after PTCA that prevented a correct geometric analysis, ${ }^{22}$ densitometry was proposed, instead of geometric quantitation, to evaluate PTCA results. Studies in phantoms have found that videodensitometry can accurately measure stenosis dimensions. ${ }^{7-9}$ In contrast, our clinical data showed that variability of videodensitometry is greater than that of geometric methods when we consider inter- or intraobserver variability either after PTCA or after a 6-month follow-up period. Moreover these results confirm a poor correlation between densitometric relative area $(r=$ 0.626 and 0.719 for intra- and interobserver test, respectively) in orthogonal views, as previously reported by other investigators. ${ }^{11,12}$

A nonlinear relation between film optical density and contrast medium thickness are caused by $\mathrm{x}$-ray scatter, beam hardening, nonuniform brightness, effects of panning, inhomogeneous contrast mixing or foreshortening. Also, disparate gray-scaling methods may be used by different digital systems. These can explain the discrepancies between the results observed in the ideal conditions of phantom studies and those obtained in unselected clinical applications. Previous reports, which showed reliability of videodensitometry, were generally performed in highly selected, symmetric lesions ${ }^{10}$ and without foreshortening ${ }^{8}$ characteristics that are common only among a minority of lesions. In contrast, in our study, no preselection of the stenoses was done and this could explain the differences between our results and the above-mentioned reports. In previous studies, ${ }^{12}$ a lack of correlation between geometric and densitometric evaluation of percent area stenosis after PTCA was shown. Inhomogeneous mixing of contrast medium and blood due to the anatomic changes of the arterial wall immediately after PTCA could have caused these results because of violation of this fundamental prerequisite for performing videodensitometry. However, our videodensitometry results were highly variable both immediately and late after PTCA

Although we found an improved reproducibility of videodensitometry when the values of orthogonal views were averaged and a good correlation between this mean and elliptical percent cross-sectional area, the results obtained through geometric analysis were always much more reproducible than those obtained through videodensitometry. We think that the poor reproducibility of videodensitometry, when applied to typical clinical studies, suggests that current approaches are not yet suitable for assessing angioplasty or other interventions.

Surprisingly, we did not observe a remarkable discrepancy in the analysis of post-PTCA and follow-up films, and this difference further diminished when biplane analysis was considered. These data support the concept that difficulties of geometric quantitative systems to describe the results of PTCA are less in practice than in theory. Biplane analysis, which has been proposed to overcome the problem of asymmetric lesions, has been shown to be highly reproducible with only small differences between immediate post-PTCA and follow-up analyses.

In conclusion, this study supports the suitability of geometric quantitative analysis for assessing coronary interventions in both research and clinical settings. Criteria are provided that allow the complete description of an arterial segment undergoing remodeling due to interventions. Of these criteria, densitometry, even when results from orthogonal views are averaged, is the least reliable. In our study, the differences in geometric analyses between post-PTCA and follow-up films were negligible, suggesting that geometric methods are most appropriate for assessing immediate and late PTCA results. Of these measurements, the mean and minimum diameter measurements are the most reliable.

\section{REFERENCES}

1. Detre KM, Wright PHE, Murphy ML, Takaro T. Observer agreement in evaluating coronary angiograms. Circulation 1975;52:979-986.

2. Zir ML, Miller SW, Dinsmore RE, Gilbert JP, Harthorne JW. Interobserver variability in coronary angiography. Circulation 1976;53:627-632.

3. De Rouen TA, Murray JA, Owen W. Variability in the analysis of coronary angiograms. Circulation 1977;55:324-328.

4. Brown GB, Bolson E, Frimer M, Dodge HT. Quantitative coronary arteriography. Estimation of dimensions, hemodynamic resistance, and atheroma mass of coronary artery lesions using the arteriogram and digital computation. Circulation 1977;55:329-337.

5. Reiber JHC, Kooijman CJ, Slager CJ, Gerbrands JJ, Schuurbiers JCH, Den Boer A, Wijns, W, Serruys PW. Computer assisted analysis of the severity of obstructions from coronary cineangiograms: a methodological review. Automedica 1984;5:219-238.

6. Mancini GBJ, Sinon SB, MoGillem MJ, LeFree MT, Friedman HZ, Vogel RA. Automated quantitative coronary arteriography: morphologic and physiologic validation in vivo of a rapid digital angiographic method. Circulation 1987;75:452-460

7. Spears JR, Sandor T, Als AV, Malagold M, Markis JE, Grossman W, Seru JR, Paulin S. Computerized image analysis for quantitative measurements of vessel diameter from cineangiograms. Circulation 1983;68:453-461.

8. Nichols AB, Gabrieli CFO, Fenoglio JJ, Esser PD. Quantification of relative coronary arterial stenosis by cinevideodensitometry analysis of coronary arteriograms. Circulation 1984;68:512-522.

9. LeFree MT, Simon SB, Mancini GBJ, Vogel RA. Digital radiographic assessment of coronary arterial geometric diameter and videodensitometric cross-sectional area. SPIE 1986;626:334-341. 
10. Serruys PW, Reiber JH, Wijns W, Brand M, Kooijman CJ, ten Katen HJ, Hugenholtz PG. Assessment of percutaneous transluminal coronary angioplasty by quantitative coronary angiography: diameter versus densitometric area measurements. Am $J$ Cardiol 1984;54:482-488.

11. Sanz ML, Mancini GBJ, LeFree MT, Mickelson JK, Starling MR, Vogel RA, Topol E. Variability of quantitative digital subtraction coronary angiography before and after percutaneous transluminal coronary angioplasty. Am J Cardiol 1987;60:55-60

12. Katritsis D, Lythall DA, Anderson MH, Cooper IC, Webb-Peploe MM. Asscssment of coronary angioplasty by an automated digital angiographic method. Am Heart $J$ 1988;116:1181-1187.

13. Killip $T$, and Principal Investigators of CASS and their associates. National Heart, I ung, and Blood Institute Coronary Artery Surgery Study. Circulation 1981;63(suppl I):I1-I-81.

14. Kavanaugh $K$, McGillem M, DeBoe SF, Pinto IMF, Mancini GBJ. The effects of video frame averaging, smoothing and edge enhancement algorithms on the accuracy and precision of quantitative coronary arteriography. Int $J$ Card Imaging 1990;5:233-239.

15. Ellis S, Sanders W, Goulet C, Miller $\mathbf{R}$, Cain KC, Lesperance J, Bourassa $\mathrm{MG}$, Alderman EL. Optimal detection of the progression of coronary artery disease: comparison of methods suitable for risk factor intervention trials. Circula- tion 1986:74:1235-1242.

16. Brown BG, Bolson EL, Dodge HT. Quantitative computer techniques for analyzing coronary arteriograms. Prog Cardiovasc Dis 1986:28:403-418.

17. Ross AM. Interpretation of coronary angiograms. J Am Coll Cardiol 1990;16:114.

18. Beauman GJ, Vogel RA. Accuracy of individual and panel visual interpretations of coronary arteriograms: implications for clinical decisions. $J$ Am Coll Cardiol 1990;16:108-113.

19. Goldberg RK, Kleiman NS, Minor ST, Abukhalil J, Raizner AE. Comparison of yuantitative coronary angiography to visual estimates of lesion severity pre and post PTCA. Am Heart $J$ 1990;119:178-184.

20. Reiber JHC, Serruys PW, Kooijiman CJ, Wijns W, Slager CJ, Gerbrands JJ, Schuurbiers JCH, Den Boer A. Hugenholtz PG. Assessment of short-, mediumand long-term variations in arterial dimensions from computer-assisted quantitation of coronary cineangiograms. Circulation 1985;71:280-288.

21. Harrison DG, White CW, Hiratzka LF, Doty DB, Barnes DH, Eastham CL Marcus ML. The value of lesion cross-sectional area determined by quantitative coronary angiography in assessing the physiologic significance of proximal left anterior descending coronary arterial stenoses. Circulation 1984;69:1111-1119. 22. Block PC, Myler RK, Stertzer S, Fallon JT. Morphology after transluminal angioplasty in human beings. $N$ Engl $J$ Med 1981;305:382-386 